\title{
RELATO PESSOAL: \\ COM UM SEIXO ROLADO NA SALA DE VISITAS (OU "LIKE A ROLLING STONE"): DE SABER ACADÊMICO E SABERES TRADICIONAIS NA POSSÍVEL PRODUÇÃO DE ALGUMA EDUCAÇÃO ESCOLAR INDÍGENA
}

\author{
José Augusto Laranjeiras Sampaio ${ }^{1}$
}

\begin{abstract}
Resumo: A educação escolar indígena é um campo em que se discute bastante sobre as possibilidades de relação entre conhecimento acadêmico e conhecimentos tradicionais, em especial no âmbito da formação de professores indígenas. Numa visão a partir da Antropologia enquanto "ciência" de mediação entre diferentes "lógicas" de conhecimento, valho-me de relato autobiográfico para afirmar uma dimensão de tradicionalidade também no conhecimento dito "acadêmico", criticar as perspectivas de "articulação" ou "síntese" entre essas diferentes lógicas e defender a radicalidade da experiência da alteridade como via possível, tênue que seja, para o diálogo e as interrelações entre formas de conhecimento, tomadas aqui como diferentes cosmovisões.

Palavras-Chave: Educação indígena, Conhecimento, Tradição, Ciência, Cosmovisão.
\end{abstract}

Abstract: Indigenous school education is a field in which the possibilities of relationship between academic and traditional knowledge is examined, especially in what relates to forming indigenous teachers. Considering Anthropology as a science of mediation between different "logics" of knowledge, I make use of an autobiographic report to assert a dimension of traditionality in the so called academic knowledge as well, criticize the perspectives of "articulation" or "synthesis" among this different logics, and defend the uniqueness of the experience of alterity as a possible way, as tenuous as it might be, to a dialogue and the interrelationships between forms of knowledge, seen here as different worldviews.

Keywords: Education, Indians knowledge, Tradition, Science, Cosmovision.

A educação escolar indígena, pensada como modalidade específica e diferenciada de educação escolar e como lugar por excelência de experiências interculturais em educação, é frequentemente tematizada como um

1 Professor de antropologia na Universidade do Estado da Bahia (UNEB/Campus I, Salvador). Endereço eletrônico: guga@anai.org.br. - Relato baseado em fala proferida em participação na mesa-redonda "Saber Acadêmico e Saber Tradicional", na sessão de abertura do curso superior de Formação Intercultural de Educadores Indígenas (Fiei) da UFM G, em Belo Horizonte, em setembro de 2006, para um público dominantemente de professores indígenas ingressantes no curso; coordenada pela Profa. Dra. Márcia Spyer Resende, também coordenadora do curso, e que teve também a participação de Gersem Luciano, antropólogo e professor indígena da etnia Baniwa. 
campo de interlocução entre os assim chamados "saber acadêmico" e "saber tradicional".

Por sua vez os antropólogos, profissionais regularmente convocados a participar de iniciativas em educação escolar indígena, são habitualmente percebidos como agentes do campo do "saber acadêmico" cuja esfera de conhecimento específico incide diretamente sobre o "saber tradicional" e, portanto, como personagens por excelência do referido campo de interlocução entre saberes, ainda que marcadamente a partir de um dos seus polos.

Chamado a participar desse debate a partir desse lugar de antropólogo, opto entretanto por fazê-lo sob a forma de um relato pessoal.

Tento aqui, de um modo ou outro, assumir esse lugar de quem fala mais explicitamente a partir de um saber acadêmico, mas reconhecendo que o tema seja melhor tratado a partir da relação entre saberes vividos; e neles da relação entre saber acadêmico e, podemos dizer, saberes tradicionais. Acho que se deve sempre falar de saber tradicional no plural, são saberes tradicionais. Do acadêmico ainda dá para falar no singular, porque há uma certa ordem interna que unifica esse saber. Mas o tradicional não, 0 tradicional tem que ser dito no plural: são saberes tradicionais. 0 que inclui o saber acadêmico, que, de um certo modo, é o nosso saber tradicional. Nós também temos a nossa tradição na academia; então o saber acadêmico é o nosso saber tradicional; é um dos muitos saberes tradicionais.

Pensando então no meu lugar de antropólogo nesse debate, eu resolvi - e não sei se vou fazer isso adequadamente - assumir o lugar de alguém que foi criado e treinado desde criancinha a pensar como se pensa na academia. A pensar segundo os padrões de cosmovisão que a ciência preside. Eu sou filho de pais intelectuais, médicos e agnósticos. Nunca tive nenhuma formação religiosa em toda a minha vida. Não tive e não tenho até hoje. Penso que esse é um saber como outro qualquer: você aprende ou não aprende. Eu não aprendi. Então não aprendi e assim não tenho esse saber. E sou um antropólogo; e a Antropologia é um desses saberes acadêmicos, compartimentado e especializado. É uma disciplina que produz uma tecnologia. E minha cosmovisão vem basicamente daí.

Tentarei começar pela ideia de diálogo intercultural, algo que aprendi e que pratico. E que é para o que acho que a Antropologia serve: para produzir tecnologias de diálogo intercultural; o que não deixa de pressupor uma certa hierarquia, porque quando nos colocamos na posição de antropólogos, capazes de assumir, promover e administrar esse diálogo intercul-

178 Número temático: M etodologias de pesquisa em ciências sociais e humanas. A Cor das Letras 
tural, estamos nos colocando, de todo modo, acima ou de fora dos outros sujeitos todos presentes nesses campos de diálogo. Mas, pelo menos, acho que, se tem alguma utilidade o tipo de saber ou conhecimento que a Antropologia produz - utilidade ou sentido - seria esse o de produzir tecnologias de compreensão de diferenças; de compreensão de diversidades; 0 que significa produzir possibilidades de diálogos entre diferentes cosmovisões.

Isto é algo muito complicado, porque quando eu vejo se falar de diálogos interculturais, me dá um temor muito grande de que se esteja pensando em uma possibilidade de se produzir sínteses. Muitas vezes conversando com quem trabalha com educação indígena me vem esse temor: Será que o pessoal está querendo articular o saber acadêmico e os saberes tradicionais? Ver como fazer isso na escola? Como a escola indígena vai reunir esses dois mundos?... Tenho medo que as pessoas pensem que seja possível fazer uma síntese, porque se você produz síntese, ou seja, se você transforma o que era dois em um, acabou-se o diálogo. 0 diálogo só existe enquanto houver dois diferentes. Se você pega dois diferentes e transforma em uma coisa só, acabou a diferença e, consequentemente, o diálogo. Então, para que se preserve a diferença e o diálogo, por favor, nada de sínteses e articulações. Deixemos que as coisas sejam diferentes mesmo; pensemos que vão continuar sendo diferentes mesmo. Mas, ainda que diferentes, possam dialogar e produzir algum nível de entendimento que não vai produzir síntese.

Quando penso a ideia do diálogo intercultural, penso muito em uma personagem da minha vida, que foi minha babá. E penso nela porque, quando penso que devo ter algo a dizer sobre saberes tradicionais, eu fico pensando comigo mesmo que o único modo como eu tenho lidado com isso é como antropólogo. 0 antropólogo lida com saberes tradicionais enquanto objetos; objetos de pesquisa. Do mesmo modo como o astrônomo lida com as estrelas, que o botânico lida com as plantas, o antropólogo lida com saberes tradicionais; como algo que a gente objetifica. É nosso objeto, sobre 0 qual nós produzimos o nosso conhecimento. Produzimos conhecimentos nossos sobre os saberes dos outros. E a gente tem a expectativa, a crença e a esperança que esse nosso saber sobre os saberes dos outros nos ajude a entender os outros e a que os outros nos entendam.

Mas nossa ciência é só isso. Ou seja, para nós, que não estamos dentro da escola indígena, essa questão de como articular esses saberes na escola não se coloca para nós enquanto profissionais: Nós estamos aqui, 
enquanto cientistas, os saberes tradicionais estão lá, são coisas interessantes e ricas, e são nosso objeto de conhecimento. Nós antropólogos nos debruçamos sobre os saberes tradicionais para conhecê-los através dos nossos procedimentos científicos, e, com isso, conseguimos produzir coisas que me parecem muito interessantes. Nós catalogamos, classificamos, organizamos, interpretamos os saberes tradicionais; lançamos um olhar externo sobre o tradicional e 0 analisamos. Nós não temos muita preocupação - pelo menos enquanto antropólogos mais clássicos - de tentar responder como esses saberes podem se articular na escola indígena. Quando nós conseguimos ir um pouco além desse nosso meio profissional mais estrito, de estar de fora, conhecendo o outro e seu saber, nós podemos apenas pretender 0 que eu disse anteriormente: que, a partir de nossa tecnologia e de nossa possibilidade de produzir conhecimento útil, a partir do que sabemos sobre o outro - de como o outro pensa, como é a cosmovisão do outro - estejamos mais qualificados para produzir diálogos com esse outro. Mas esse outro será sempre outro, eles lá e nós aqui. Não tem síntese possível.

E aqui começa a história da minha babá, e acho que vou dizer do meu saber tradicional: eu, menino filho de dois doutores sem religião, desde criancinha aprendi a ver o mundo como a ciência vê o mundo. E como toda criança, eu adorava ouvir histórias. E eu ouvia histórias dos meus pais e ouvia histórias também da minha babá. Ela era uma negra, do Recôncavo Baiano, e que também sabia contar histórias. E as histórias que eu ouvia dos livros me metiam muito medo; eu era muito medroso. Comecei a ter medo de lobo mau, da bruxa malvada, e a história do patinho feio me fazia chorar profundamente, porque eu me identificava com o patinho. E meus pais me explicaram: "Guga, você não precisa ter medo de bruxa e nem de lobo mau; eles não existem. Isso é só história". É algo que todos aprendemos: que a fiç̧ão é ficção. E a graça da ficção é essa: ter uma ligação com a realidade mas continuar sendo ficção. Então aprendi desde criançinha que lobo mau não existe, bruxa não existe, que é só historinha. Continuei então gostando das historinhas, claro, como todo mundo. Mas a minha babá, Baía, me contava histórias "do tempo que os bichos falavam". Ela tinha um acervo imenso de histórias do tempo que os bichos falavam. E eram todas histórias indígenas na origem. Pelo menos os bichos são todos brasileiros: histórias da onça com o macaco, do sapo com o urubu... muitas e muitas histórias e muito mais interessantes que os contos de fadas. Mas um belo dia eu cometi a imprudência de demonstrar para Baía que, na minha visão 180 Número temático: M etodologias de pesquisa em ciências sociais e humanas. A Cor das Letras 
de mundo, na minha cosmovisão, nunca houve um tempo em que os bichos tivessem falado. Foi em um simples comentário que fiz, mas em que deixei escapar essa minha visão de mundo. E para minha surpresa ela se revoltou e falou: "não vou mais lhe contar historinha nenhuma; porque você não acredita!" E eu perguntei: "mas você acredita? Você acha, Baía, que algum dia os bichos falaram?" E ela me respondeu que acreditava, sim; e pensei comigo mesmo: "e falavam português!" Esse episódio produziu um certo rompimento entre mim e Baía. Rompimento para mim muito doloroso; e acho que para ela também. Ela disse: "você fica aí ouvindo as minhas histórias e depois fica mangando delas. Você está mangando das minhas histórias porque você não acredita nelas." E eu dizia: "mas, Baía, como vou acreditar que bichos falavam? Que coisa absurda!". E eu tentei convencê-la do meu ponto de vista, mas a única coisa que tive como resultado disso foi perder as histórias. Para a minha profunda tristeza ela nunca mais me contou histórias do tempo que os bichos falavam. Eu precisei crescer e virar antropólogo para poder ter de novo o direito de ouvir histórias do tempo que os bichos falavam; e com o cuidado de ter aprendido a não mangar.

Só que não tenho mesmo aquela cosmovisão, que não é minha, mas que é algo com que posso dialogar, que posso entender e admirar, que posso valorizar. Mas não é minha cosmovisão, é outra.

Trago essa minha história com Baía como exemplo porque acho que isso é que é possível. Porque precisei crescer e virar antropólogo para entender que eu posso gostar muito de histórias do tempo que os bichos falavam, mesmo que minha cosmovisão me informe que, de fato, bichos jamais falaram. Ou, melhor, me informe que não tem importância. Não tem importância nenhuma para eu gostar ou não das histórias, para entendê-las, saber se aquilo pode ter sido verdade ou não. Depois que aprendi, como antropólogo, o que são os ritos e os mitos, que tem coisas que não são nem verdade e nem mentira, que estão acima da nossa dicotomia entre verdade e mentira: nossa dicotomia ocidental. Penso que seja deste modo que se pode produzir diálogos, jamais sínteses.

Há outros personagens muito importantes na minha vida que eu poderia tomar como exemplos. A minha ligação com Belo Horizonte e Minas Gerais, por exemplo, está no meu saber tradicional. De algum modo constitui minha tradição desde criancinha e acaba se construindo em mim como um saber tradicional, me informando outras coisas que eu aprendi. Penso muito também no meu tio... Desde os cinco anos de idade que eu vou muito a Belo Horizonte. Nasci com um glaucoma e BH era, e é até hoje, um 
centro importantíssimo para o tratamento de glaucoma. Então desde muito pequeno que ia a $\mathrm{BH}$ a cada seis meses (Até hoje dou jeitos de continuar fazendo isto...). E isso, ao contrário do que se possa imaginar, era algo muito prazeroso. Sempre adorei ir a Belo Horizonte. Eu era um menino muito amado pelos meus pais e, ir para lá para tratar do glaucoma, algo ameaçador, era muito prazeroso. Eram as minhas férias e sempre fui muito acolhido pelas duas famílias que eu tenho lá. $E$, assim, outro personagem que participou da minha infância foi meu tio, que era meu médico. Um cirurgião altamente competente, um pesquisador de ponta na medicina, um cientista mesmo, um professor e um cirurgião de mão cheia. E esse meu tio é um sujeito profundamente religioso e católico. É um cara que estava todo domingo na missa, que, antes de entrar para a sala de cirurgia, rezava. $E$, quando eu era menino, esse meu tio era um personagem meio incompreensível para mim: Como é que ele era um grande cirurgião, um grande cientista, e ia à missa?... Depois eu entendi, depois que virei antropólogo, entendi. Na verdade a cosmovisão do meu tio, aquela que ele ganhou desde criancinha com a família dele, é religiosa. Ele é católico desde criancinha e o catolicismo continua informando a visão de mundo dele para o resto da vida. E o fato dele ter se tornado um cientista cirurgião não alterou isso. Ele pode continuar sendo católico sempre e ter se tornado um cientista e um médico totalmente competente em sua medicina. Ele é um daqueles cirurgiões que diz: "eu opero, mas quem cura é Deus"; o que não bate com a minha visão de mundo; é a dele. Mas só depois de "gente grande" que eu aprendi a entender meu tio e admira-lo ainda mais, mas eu não penso como ele. Ele é muito diferente de mim. Ele é outra pessoa, com outra visão de mundo, mas a qual eu respeito e com a qual sou capaz de, de algum modo, dialogar. Não acho possível produzir nenhuma síntese, nem entre mim e minha babá, nem entre mim e meu tio. Mas acho interessantíssimo dialogar com o que eles são e representam e poder construir muitas cumplicidades com eles também.

Há muitas histórias que eu poderia contar, mas vou contar só mais uma: uma das vezes que eu fui a Belo Horizonte, com uns dez anos de idade, fui com outro tio na Serra da Piedade. Estavam construindo a estrada que sobe a serra e meu tio tinha uma empresa de tratores trabalhando lá. Na volta da Serra da Piedade ele parou no Rio das Velhas, no caminho de Sabará, onde tinha também algumas máquinas dele trabalhando. E foi a primeira vez na minha vida que eu estive na beira de um grande rio. Para os mineiros isso talvez pareça estranho. Eu já me entendi por gente vivendo 182 Número temático: M etodologias de pesquisa em ciências sociais e humanas. A Cor das Letras 
com o mar do meu lado, dentro dele, mas um grande rio, só com dez anos de idade. E, por causa das obras de dragagem, estava cheio de pedrinhas do rio na margem; e eu comecei a olhar aquelas pedras e analisá-las e percebi que eram todas redondas. E me perguntei por que aquelas pedras eram todas redondas. Então meu pai me explicou, cientificamente, que o rio produz movimentos e que a água, com sua força, vai limando as pedras e elas ficam todas redondinhas. Aprendi o nome delas: "seixos rolados". E aí guardei algumas daquelas pedras no meu bolso e elas foram comigo até Salvador. E, especificamente uma, que eu achei mais interessante, eu achei de dar para a minha babá de presente. E eu disse: "Baía, eu trouxe para você uma pedra de presente. Uma pedra de um Rio chamado Rio das VeIhas." E dei a pedra para ela e, bem, me esqueci desse fato. Eu tinha dez ou onze anos de idade... Baía morreu em 1986, quando eu já era antropólogo. Ou seja, se o presente foi em 67 ou 68, passaram-se quase vinte anos até sua morte. Um dia, minha mãe me perguntou se eu lembrava de ter dado uma pedra para Baía, lá do Rio das velhas. Só então me lembrei desse fato. E minha mãe continuou: "pois é, até morrer, Baía cuidou dessa pedra. E ela achava que era importante cuidar dessa pedra para você ficar bem. E, pouco antes de morrer, ela me devolveu a pedra me pedindo que eu continuasse cuidando dessa pedra para que você continue bem. Mas, no fundo, 0 que ela queria dizer é que você é quem deveria cuidar da pedra." E eu disse: "Eu? E como é que eu cuido da pedra?" M inha mãe disse que Baía havia ensinado a ela que aquela pedra era de rio e, por isso, precisava sempre de água doce e corrente. Enfim, havia toda uma tecnologia do candomblé, já que Baía tinha um conhecimento de candomblé, para cuidar da pedra. Então recebi a incumbência de cuidar da pedra e não dei muita importância para isso, achei meio chatinho até. Para resumir a história, nesses últimos 20 anos, desde que recebi essa missão de cuidar da pedra, eu passei vários anos "estudando" a pedra em mim; estudando o que representa a existência e a história dela. Atualmente essa pedra está na minha sala de visitas, dentro de uma cumbuquinha, com água, que minha mãe comprou para ela e eu não troco por nenhuma outra. A minha namorada fez para mim uma fontezinha onde a água cai em cima da pedra. E eu adoro ter essa pedra na minha sala de visitas! E por que eu gosto disso? É porque eu acho que, se eu não cuidar da pedra, vai me acontecer algo de ruim? Não, rigorosamente, não é. É porque a existência dessa pedra me conecta com as minhas memórias mais caras; ela me liga às coisas que me são queridas. Como, por exemplo, a minha babá. É como se eu, admitindo essa pedra na minha sala 
de visitas, tivesse resgatado o que eu perdi quando não consegui ouvir as histórias do tempo em que os bichos falavam.

Essa pedra e esse sentimento são, de um certo modo, o meu saber tradicional. Saber tradicional de vida. E talvez eu tenha virado antropólogo para aprender a lidar com essas coisas que, enquanto criança, me incomodavam. Me incomodava Baía pensar que um dia os bichos falaram; me incomodava meu tio ser um cirurgião de ponta e ir para missa. Acho que eu acabei conseguindo resolver alguns dos meus dilemas virando antropólogo. Eu continuo sendo o que eu fui criado para ser desde criancinha: um sujeito que não é religioso, que não tem tecnologia religiosa nenhuma, que não pensa em termos religiosos em nada na vida. Às vezes me perguntam: Guga, quando é que você reza? E eu digo: nunca. Eu não sei fazer isso, não aprendi. Se tem um sujeito que poderia ser chamado de racionalista, em termos científicos, eu sou esse tipo de pessoa. Eu sou um antropólogo, e a Antropologia é uma ciência, uma disciplina acadêmica, e que marca a minha identidade. E ela me serve também como uma solução para conflitos que eu tinha desde criança e que, através dela, da minha ciência, eu aprendi a lidar. Eu aprendi a ter essa tecnologia de conversar com o diferente e dialogar com aquilo que me é estranho.

E eu aprendi que saberes tradicionais são aqueles saberes que estão encarnados nos afetos das pessoas e das coletividades. São saberes que marcam a visão de mundo desses grupos e que não podem ser mexidos. $E$ que se forem mexidos dá uma confusão muito grande. E qualquer pessoa, qualquer grupo social, nós da academia também, temos os nossos próprios saberes tradicionais. A minha Antropologia passou a ser em mim também 0 meu saber tradicional, coerente com o que eu aprendi desde pequenininho com meus pais. Desde que eu ouvi contos de fadas e aprendi a pensar que bruxas e fadas não existem. Isso é coerente com o que eu sou até hoje.

E até hoje, por exemplo, eu adoro ouvir cantatas de Bach, que é música religiosa, mas que eu aprendi a gostar desde pequenininho, ficando quietinho, de olhos fechados, no sofá, juntinho com o meu pai, que foi quem me ensinou a gostar de Bach. E até hoje eu gosto muito de ouvir Bach, porque eu sou capaz de compreender que isto tem a ver com 0 afeto entre mim e meu pai; e que tem a ver também com a nossa compreensão do afeto de Bach - pela humanidade e pelo seu Deus - que ele tão maravilhosamente expressa na sua música. É um diálogo e um entendimento, silenciosos até, entre mim e meu pai, entre nós e Bach, e entre nós três e o humano... Mas é claro que isto não é plenamente acessível nem inteligível a 
todo mundo; foi construído, afetiva e intelectualmente, dentro de um certo contexto familiar e cultural, que têm também lá a sua cosmovisão...

De outro jeito, eu me tornei capaz de compreender o que os índios que pesquisei, e com os quais trabalho até hoje, sentem quando fazem um toré; quando cantam e dançam um toré. Aprendi a entender, mas não a sentir, é claro. Posso até me emocionar assistindo a um toré, mas jamais vou sentir o que eles sentem - não é como Bach para mim. (Não é como os Rolling Stones, com quem aprendi a me identificar em minha rebeldiazinha de adolescente classe média urbano da década de 1970, e que até hoje me emocionam profundamente...) Mas o fato de poder, como antropólogo, compreender o que eles, os índios, sentem - 0 que o toré significa de força e de união para as suas lutas - me faz capaz de me tornar, afetiva, intelectual e politicamente, aliado e cúmplice dessas lutas. Aí se produzem diálogos, entendimentos e cumplicidades, mas eu e eles permanecemos essencialmente outros, essencialmente muito diversos.

Agora vem a pergunta: como a escola indígena pode lidar com isto? Com estes dois mundos? E a minha resposta é: não sei, não sei mesmo. Não sei nem se é possível. Em princípio acho perigoso qualquer pretensão de produzir sínteses. Tenho ouvido muitos discursos de etno-isso, etno-aquilo, que pretendem articular diferentes lógicas de conhecimento; que acham viável se produzir uma possibilidade de junção. E, como eu já disse em outro lugar, quando se tenta fazer isso, pode-se resultar em uma colcha de retalhos mal costurada, em que o conhecimento do outro te interessa apenas em parte, o resto, que não te parece válido, você joga fora. Ou dá nisso ou dá em algumas esquizofrenias: tenho alguns colegas-amigos que acham que vão virar índio. Tem muita gente que acha que vai virar índio. Aí vai para 0 mato, adota alguns costumes indígenas, alguns rituais... Têm alguns que até viram índio mesmo, mudam de cosmovisão e passam para o outro lado. Mas passar para o outro lado não é produzir diálogo nem síntese; é passar para o outro lado. Você deixa de ser o que é e passa a ser 0 "outro" ou, pelo menos, a caricatura do outro. Mas virar caricatura do outro não é produzir diálogo nem entendimento, é mudança de lado somente. Se você realmente quiser dialogar, não mude de lado. Fique onde você está e encare o outro como outro mesmo, como diferente mesmo, e tente conversar. Tente entender o que ele pensa, que não é nem vai ser o que você pensa, mas vocês talvez possam fazer alguma coisa juntos. Até, quem sabe, uma escola, essa coisa tão nossa. 
Eu acho que não dá para saber como será a escola indígena porque são muitos os povos, são muitas as cosmovisões, muitas diferenças. Qualquer projeto global para a escola indígena será em si perigoso ou inócuo. Cada sociedade e cada etnia é que têm que inventar a sua escola, a partir da sua cosmovisão. Que, em paz consigo mesmas e com suas visões de mundo, possam inventar a sua escola. E, se for o caso de fazer uma colcha de retalhos, que seja uma colcha de retalhos delas, dessas sociedades e etnias. Por isso eu não tenho respostas a essa pergunta. 0 que posso dizer é que como cientista, porque sou cientista, trata-se de tentar usar a minha capacidade de produzir conhecimento cientifico para tentar produzir tecnologias de diálogo com os outros. E isso tem limites, limites grandes. Em alguns pontos funciona e para algumas coisas não funciona. Não sei se funciona para inventar um jeito novo e especial de se fazer escola. A experiência vivida ou a ser vivida pelos professores e outros pensadores indígenas é que talvez venha a produzir respostas para isso. 